\title{
A Compact Dual Band Monopole Antenna using Defected Ground Structure
}

\author{
Radhika Shandilya \\ Thapar Institute of Engineering and Technology \\ Patiala \\ India
}

\author{
Rajesh Khanna \\ Thapar Institute of Engineering and Technology \\ Patiala \\ India
}

\begin{abstract}
A very compact microstrip fed dual band antenna is designed for WLAN and WiMAX application. The antenna offers a wide bandwidth of $1.28 \mathrm{GHz}$ from $2.396 \mathrm{GHz}$ to $3.678 \mathrm{GHz}$. The antenna resonates at around $2.53 \mathrm{GHz}$ and $3.37 \mathrm{GHz}$ defined by $10 \mathrm{~dB}$ return loss which covers WLAN $(2.4 \mathrm{GHz})$ and WiMAX $(3.5 \mathrm{GHz})$. The antenna has a rectangular patch with dual inverted L-Shaped strips and is fed by a cross shaped strip line. Defected Ground Structure is used in this antenna. The designed antenna has a small size of $18.6 \times 30.1$. The structure is symmetrical along vertical axis.
\end{abstract}

\section{General Terms}

Monopole antenna, Antenna theory.

\section{Keywords}

Microstrip fed antenna, dual band monopole antenna, defected ground.

\section{INTRODUCTION}

Wireless communication is widely used today in various fields. Many techniques have been developed to achieve multiple bands. Some of the antennas which are widely used in third generation mobile systems today are planar patch inverted F (PIFA), printed dipole antenna and planar monopole antenna. Among these antennas, the planar monopole antennas have especially received much more interest than others owing to their potential in providing various required radiation features of multiband, wide bandwidth, and low profile for a communication system [9]. However, such kinds of antennas mostly need a large size of ground plane, which is often printed on the different side of the substrate from the radiating plane, and thus a via-hole connection is always necessary for feeding the signal and this increases the manufacture difficulty and cost. Defected Ground Structure has recently been investigated and found to be simple and effective method to reduce the antenna size as well as excite additional resonant modes [1]. In this paper a very compact dual band antenna is presented. Emphasis is given to the antenna symmetry and the defected ground structure.

\section{PROPOSED COMPACT DUAL BAND MONOPOLE ANTENNA USING DEFECTED GROUND STRUCTURE}

In this paper, microstrip fed dual band monopole antenna with defected ground structure is discussed and simulation studies has been carried out by varying the geometrical parameters of the antenna and its effect on the performance of the antenna is studied.

\subsection{Antenna Design}

Antenna design in Figure1 (a) and Figure 1 (b) shows the top and the bottom view of the microstrip fed monopole antenna. The antenna is excited by the microstrip feedline and is printed on the FR4 substrate with a thickness of $1.6 \mathrm{~mm}$ and relative permittivity of 4.4.The radiator and ground plane are etched on the opposite sides of a substrate. The radiator comprises a rectangular patch which is protruded with two inverted L Shaped strips from its upper sides. Unlike the generally used rectangular plane, the ground is defected by two equal shaped slots approximately embedded from its left and right. These slots are introduced to increase the excitation of the resonant modes and improve the impedance matching condition for the antenna. A general approach of representing a DGS in terms of equivalent parallel LC or RLC circuit has been explored. The larger rectangular defect on either side of the line causes effective series inductance $\mathrm{L}$ and the narrow slot beneath the line produces a gap capacitance $\mathrm{C}$ in parallel with $\mathrm{L}$ as shown in Figure 2(a). Once the equivalent $\mathrm{L}$ and $\mathrm{C}$ values are known DGS characteristics can be determined.

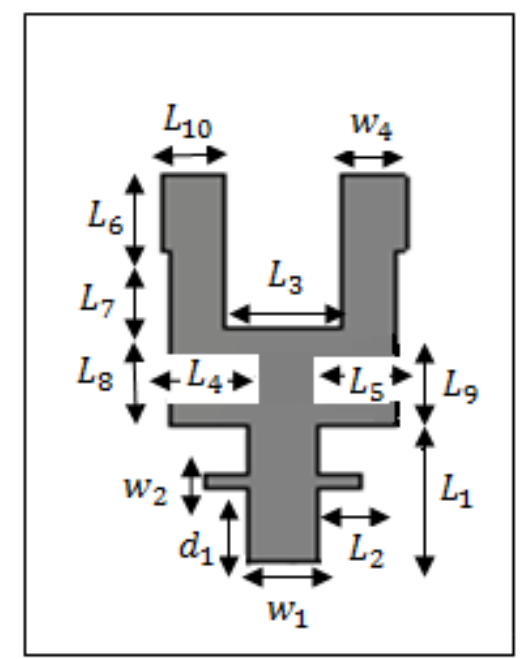

Fig 1 (a) Top view of the antenna $\mathrm{L}_{4}=5 \mathrm{~mm} \mathrm{~L}_{5}=5 \mathrm{~mm} \mathrm{~L}_{6}=4.6 \mathrm{~mm} \mathrm{~L}_{7}=5.3 \mathrm{~mm}$ $\mathrm{L}_{10}=3.5 \mathrm{~mm} \mathrm{~W}_{1}=3.5 \mathrm{~mm} \mathrm{~W}=2.6 \mathrm{~mm}$ 


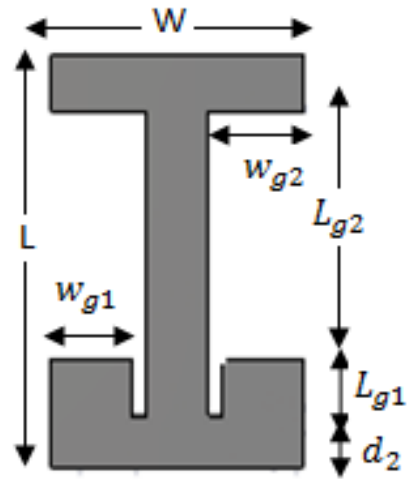

Fig 1 (b) Bottom view of the antenna

$\mathrm{L}=18.1 \mathrm{~mm} \mathrm{~W}=30.1 \mathrm{~mm} w_{\mathrm{g} 1}=5.55 \mathrm{~mm} w_{\mathrm{g} 2}=26.5 \mathrm{~mm}$ $\mathrm{L}_{\mathrm{g} 2}=20.8 \mathrm{~mm} \mathrm{~L}_{\mathrm{g} 1}=4.4 \mathrm{~mm} \mathrm{~d}_{2}=2.8 \mathrm{~mm}$

The response of a single pole LPF can be matched with the response of one pole Butterworth LPF as shown in Figure 2 (b). The reactance of the equivalent circuit in Fig.2 is given as [1]:

$$
\mathrm{X}_{\mathrm{LC}}=\frac{1}{\omega_{0} C}\left(\frac{\omega_{0}}{\omega}-\frac{\omega}{\omega_{0}}\right)
$$

where $\omega_{0}$ is the angular frequency resonance.

The reactance of LPF in Figure 2 (b) is given by:

$$
\mathrm{X}_{L}=\omega_{1} Z_{0} g_{1}
$$

where $\omega_{1}$ is the normalized angular frequency, $Z_{0}$ is input and output port impedances, and $g_{1}$ is the 'prototype element'.

(a)

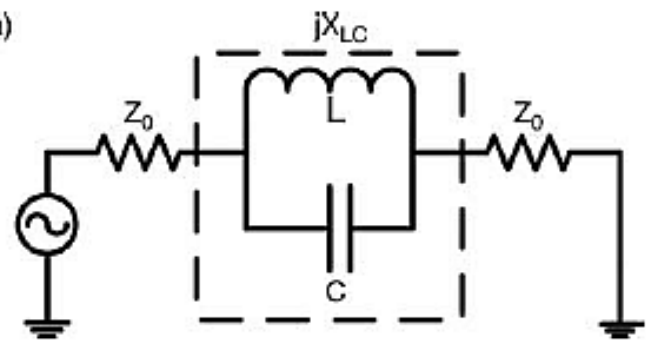

(b)

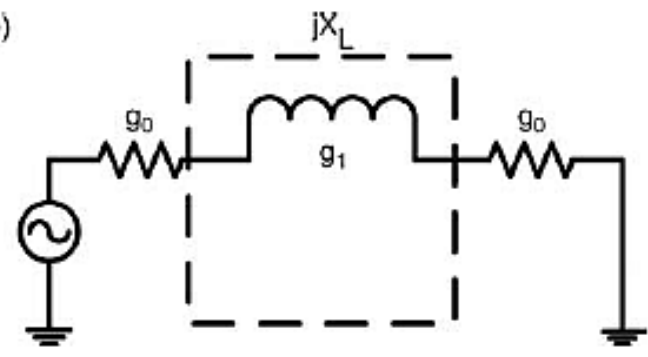

Fig 2 (a) LC equivalent circuit of a single cell dumbbell shaped DGS (b) one pole butterworth type Low Pass Filter [1]

Equating (1) and (2) at the cut off frequency

$$
\begin{aligned}
& \mathrm{X}_{L C}\left|\omega=\omega_{c}=X_{L}\right| \omega=\omega_{1} \\
& C=\frac{\omega_{c}}{Z_{0} g_{1}} \frac{1}{\left(\omega_{0}^{2}-\omega_{c}^{2}\right)} \\
& L=\frac{1}{4 \pi^{2} f_{0}^{2} C}
\end{aligned}
$$

where $f_{0}$ is the resonant frequency for DGS as well as the attenuation pole of the Butterworth prototype.

The LC modeling does not account for any losses caused by radiation or conductor/dielectric losses. A more realistic model takes an equivalent loss resistance $\mathrm{R}$ into account (as shown in Figure 3).

$$
R=\frac{2 z_{0}}{\sqrt{\frac{1}{\left|S_{11}(\omega)\right|^{2}}\left(2 z_{0}\left(\omega C-\frac{1}{\omega L}\right)\right)^{2}-1}}
$$

Where,

$$
S_{11}(\omega)=\frac{Z_{\text {in }}-Z_{0}}{Z_{O}-Z_{\text {in }}}
$$

the equivalent $\mathrm{C}$ and $\mathrm{L}$ are expressed in Equations (4) and (5) respectively.

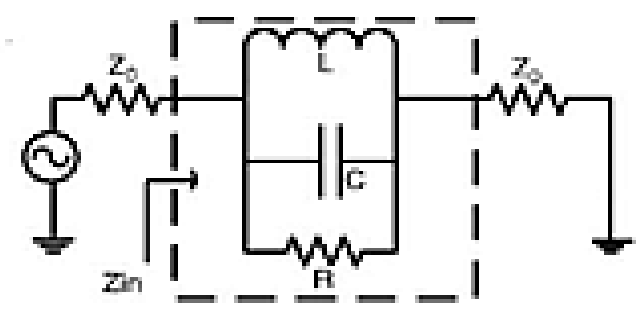

Fig 3 LCR equivalent circuit of single cell dumbbell shaped DGS.

\section{RESULTS AND DISCUSSIONS}

The measured return loss characteristics of the prototype antenna printed on FR4 substrate of dielectric constant 4.4 and thickness1.6mm using CST STUDIO SUITE is shown in Figure 4 . The simulated curve obtained shows that antenna has two resonances at 2.53 and $3.37 \mathrm{GHz}$ respectively. The performance of the antenna is studied by varying the dimensions of the structures of the antenna The First and Second band coalesce to give a wide bandwidth of $1.28 \mathrm{GHz}$ from $2.396 \mathrm{GHz}$ to $3.678 \mathrm{GHz}$ respectively. The first return loss measured is around $-23 \mathrm{~dB}$ and the second return loss measured is around $-18 \mathrm{~dB}$. Hence the proposed antenna has a good return loss characteristics.

\subsection{Gain and Directivity}

The antenna has an average moderate gain and directivity of around $2.3 \mathrm{dBi}$ and $2.45 \mathrm{~dB}$. The antenna exhibits good radiation characteristics over the operating bands. The gain and directivity of the antenna is as shown in Figure 5 and Figure 6 . 


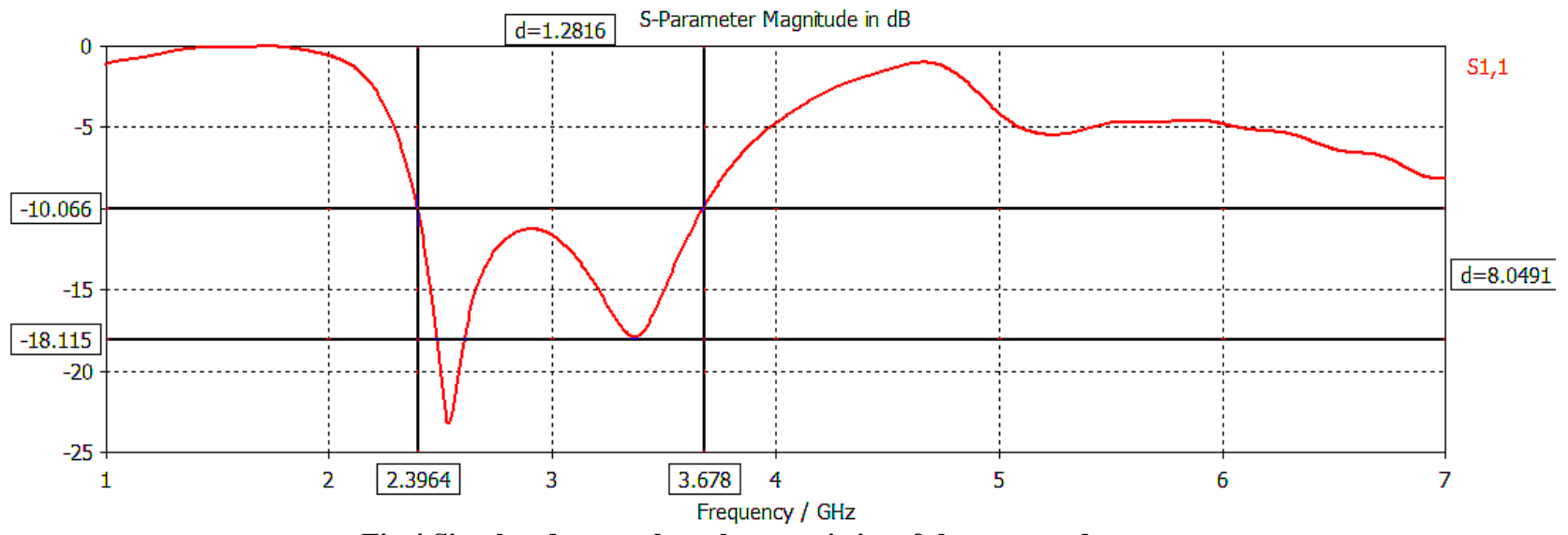

Fig 4 Simulated return loss characteristics of the proposed antenna

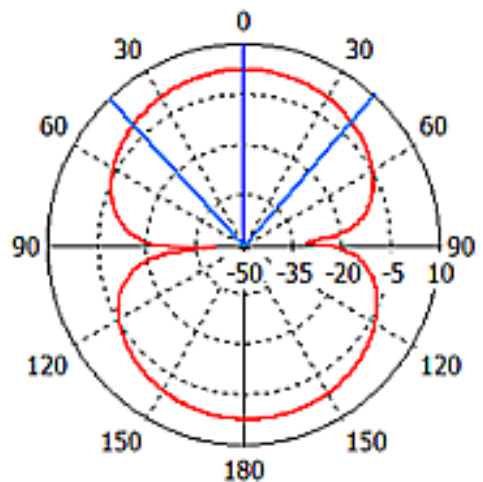

(a)

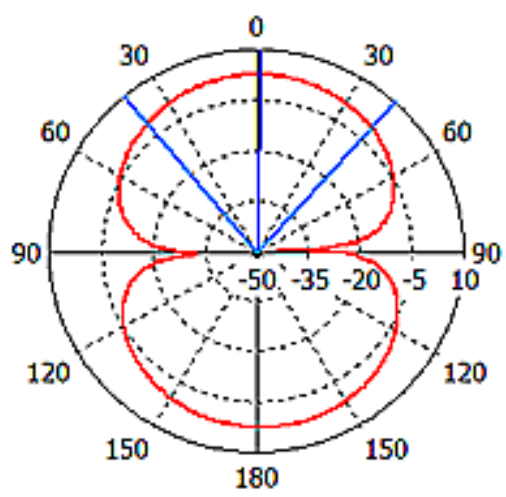

(b)

Fig 5 Directivity at (a) $2.53 \mathrm{GHz}$ (b) $3.37 \mathrm{GHz}$

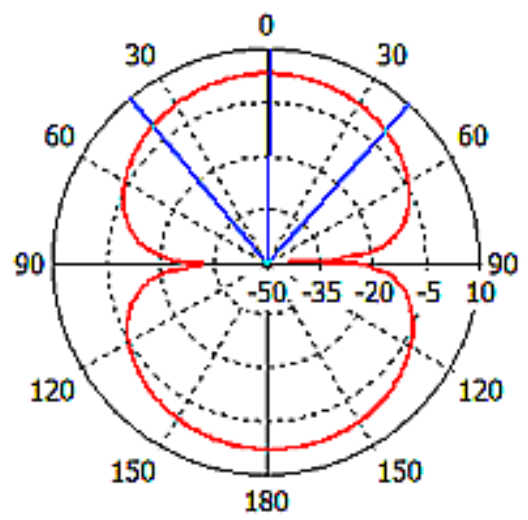

(a)

(b)

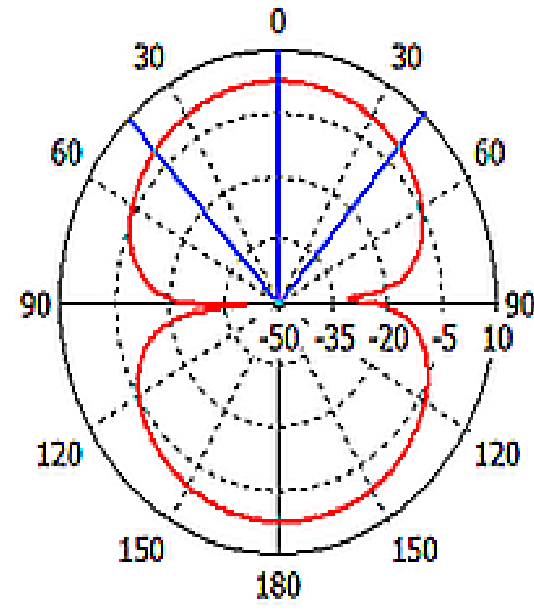

Fig 6 Gain at (a) $2.53 \mathrm{GHz}$ (b) $3.37 \mathrm{GHz}$

\subsection{Surface Current Distribution}

Surface current distribution of the antenna for the two resonant frequencies is shown in Figure 7 and Figure 8. The surface current distribution is shown for both the patch and defected ground. The surface current is distributed throughout the patch with inverted L strips. The surface current distribution on patch and defected ground is shown in Figure 7 and Figure 8.

Top and bottom view of the fabricated antenna printed on Fr4 substrate is shown in Figure 9(a) and Figure 9(b).The practical and the simulated result shows that a dual band is formed between the desired frequency range from $2.396 \mathrm{GHz}$ to $3.678 \mathrm{GHz}$. The two resonant peaks are around $-23 \mathrm{~dB}$ and $18 \mathrm{~dB}$.

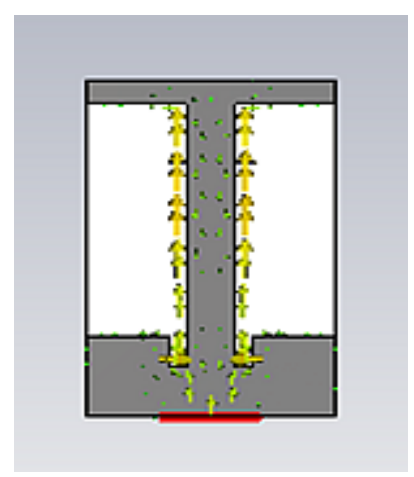

(a) 


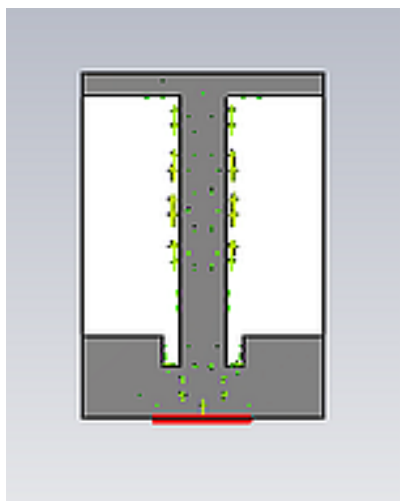

(b)

Fig 7 Surface current distribution at $2.53 \mathrm{GHz}$

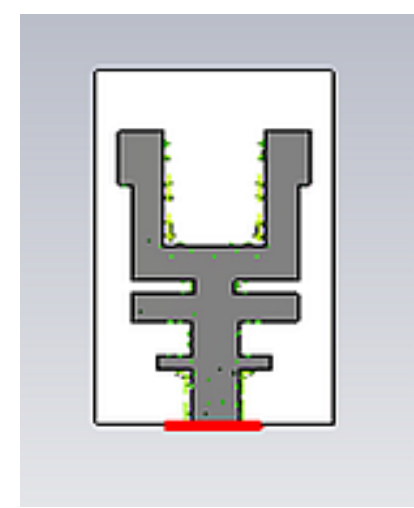

(a)

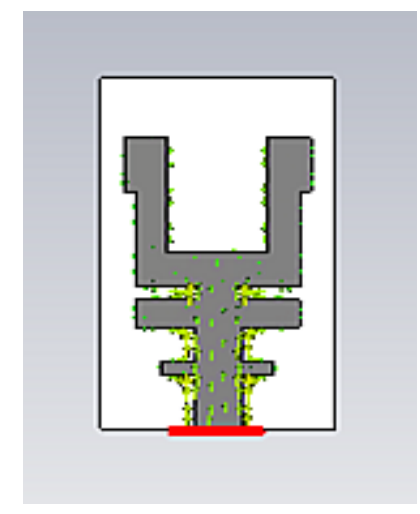

(b)

Fig 8 Surface current distribution at $3.37 \mathrm{GHz}$

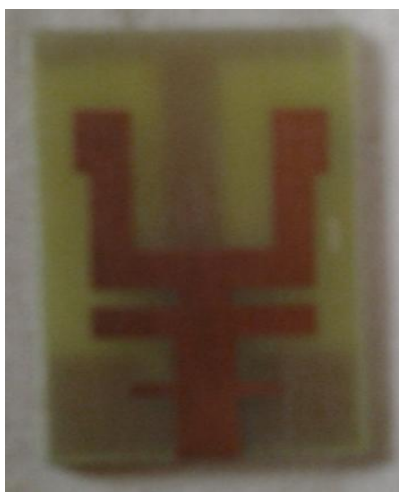

Fig 9(a) Top view of the antenna

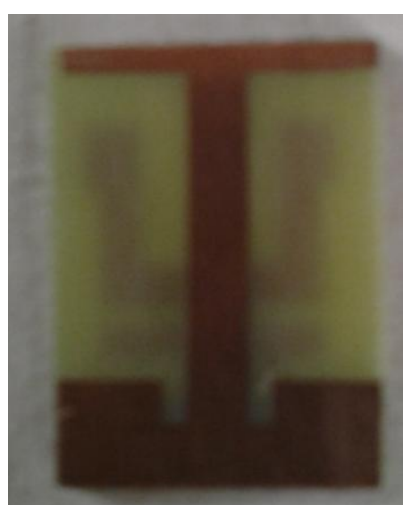

Fig 9 (b) Bottom view of the antenna

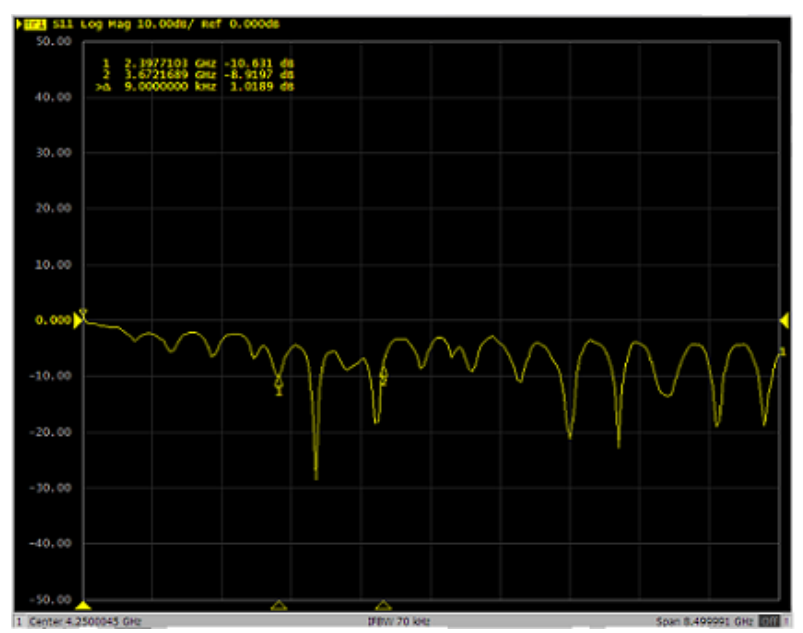

Fig 10 Practical return loss curve of the proposed multiband antenna

\section{CONCLUSION}

A compact monopole antenna is presented for WLAN and WiMAX applications. The antenna offers a wide bandwidth of $1.28 \mathrm{GHz}$. The effect of varying the dimensions of the structures i.e. DGS, the protruded strips and the cross shaped stripline, on the antenna resonant frequencies and impedance bandwidths is presented and discussed.

\section{ACKNOWLEDGEMENT}

The authors thank Thapar Institute of Engineering and Technology, Patiala for allowing us to carry out the measurements for the study of the proposed antenna.

\section{REFERENCES}

[1] Debatosh Guha and Yahia M.M Antar,"Microstrip and Printed Antennas",John Wiley \& Sons,2011.

[2] R. Garg, P. Bhartia, and I. Bahl, Microstrip Antenna Design Hand book, 1st ed. Boston, MA: Artech House, 2001, pp. 794-795.

[3] K.D Prasad, "Antenna \& Wave Propagation", 3rd Edition 2010

[4] Balanis, C.A., "Antenna Theory Analysis and Design" 3rd Edition, New Jersey: John Wiley.

[5] Yazi Cao, Member, IEEE, Bo Yuan, and Gaofeng Wang, Senior Member, IEEE“A Compact Multiband OpenEnded Slot Antenna for Mobile Handsets" IEEE 
antennas and wireless propagation letters, Vol. 10, pp. 353-357,Aug. 2011.

[6] W.-C. Liu1, M. Ghavami2, W.-C. Chung1 "Triplefrequency meandered monopole antenna with shorted parasitic strips for wireless application" IET Microw. Antennas Propag. 2009, Vol. 3, Iss. 7, pp. 1110-1117.

[7] W. C. Liu and W. R. Chen, "CPW-fed compact meandered patch antenna for dual-band operation," IEEE Electron. Lett. Vol. 40, no. 18, pp. 1094-1095, Sep. 2004

[8] Kin-Lu Wong, Senior Member, IEEE, Gwo-Yun Lee, and Tzung-Wern Chiou" A Low-Profile Planar Monopole Antenna for Multiband Operation of Mobile Handsets" IEEE Transactions Antennas and Propagation, Vol. 51, no.1, pp. 121-125, Jan. 2003.
[9] Jui-Han Lu, Senior Member, IEEE, and Wen-Chieh Chou "Planar Dual U-Shaped Monopole Antenna with Multiband Operation for IEEE 802.16e" IEEE Antennas and Wireless Propagation Lett., Vol. 9, PP. 1006-1009.

[10] Deepu.V, Rohith K. Raj, Manoj Joseph, Suma M.N, and P. Mohanan, "Compact asymmetric coplanar strip fed monopole antenna for multiband applications," IEEE Trans. on Antennas and Propog.,vol.55,no.8,pp23512357,Aug. 2007.

[11] Wen-Chung Liu, Senior Member, IEEE, Chao-Ming Wu, and Yang Dai "Design of Triple-Frequency MicrostripFed.

[12] Monopole Antenna Using Defected Ground Structure" IEEE Transactions on Antennas and Propagation, Vol. 59, no. 7, July 2011. 